\title{
NOTAS PRELIMINARES SOBRE O CONCEITO DE PAISAGEM: ENTRE A LANDSCAPE INGLESA E A LANDSCHAFT ALEM $\tilde{A}$
}

- ULISSES S. FERNANDES

Prof. Associado do Departamento de Geografia Humana do Instituto de Geografia, UERJ, Campus Maracanã; Membro Permanente do Programa de Pós-Graduação em Geografia, UERJ, Campus Maracanã. E-mail: ulisses.fernandes@uerj.br

\section{- PHILIPPE D. L. TORRES}

Doutorando do Programa de Pós-Graduação em Geografia, UERJ, Campus Maracanã. E-mail: philippe.uerj@gmail.com

Recebido em: 12/12/2020

Aprovado em: 11/01/2021

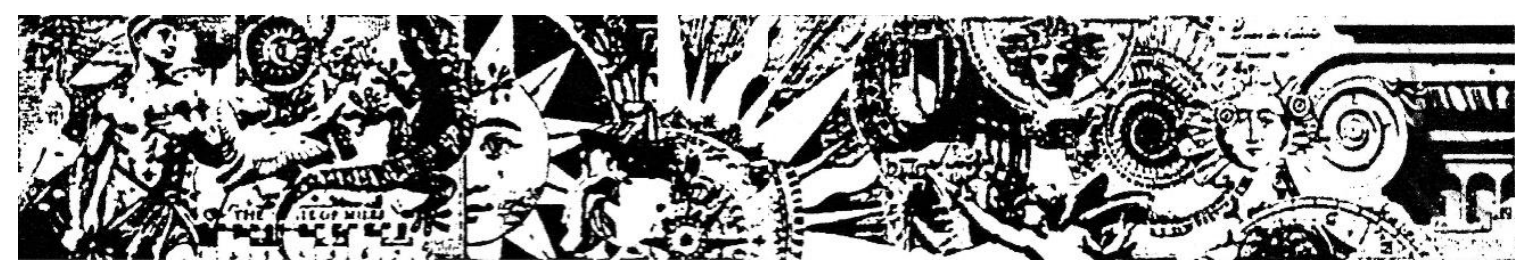

Resumo: É possível atestar uma relativamente recente retomada dos estudos de paisagem sobretudo na Geografia Cultural. Contudo, para além da importância dessa área das ciências geográficas, a paisagem já foi um conceito chave para a compreensão da natureza e da geografia do homem. Como afirma Richard Hartshorne em Perspective on the Nature of Geography (1959), porém, há um problema histórico com relação ao conceito de paisagem na etimologia alemã - Landschaft - que, apesar de nas traduções para 0 inglês assumir a palavra landscape, ambas possuem significados sensivelmente distintos. 0 presente artigo, portanto, busca reabrir as discussões no que concerne a essas diferenças fundamentais, razão de alguns ruídos, sobretudo quando chega à língua portuguesa, quando o termo alemão geralmente não foi traduzido do original, mas de suas versões inglesa e francesa. Tendo essa questão inicial, objetiva-se estabelecer preliminarmente algumas diferenças entre a landscape inglesa e a Landschaft alemã, tendo em vista o pensamento científico filosófico referente aos séculos XVIII e primeira metade do XIX.

Palavras-chave: Landscape; Landschaft; Estado Nacional; Romantismo. 


\title{
PRELIMINARY NOTES ON THE LANDSCAPE'S CONCEPT: BETWEEN THE ENGLISH LANDSCAPE AND THE GERMAN LANDSCHAFT
}

\begin{abstract}
IT IS POSSIBLE TO ATTEST A RELATIVELY RECENT RESUMPTION OF LANDSCAPE STUDIES, ESPECIALLY IN CULTURAL GEOGRAPHY. HOWEVER, IN ADDITION TO THE IMPORTANCE OF THIS AREA FOR GEOGRAPHIC SCIENCES, THE LANDSCAPE WAS ONCE A KEY CONCEPT FOR UNDERSTANDING THE NATURE AND THE MAN'S GEOGRAPHY. AS RICHARD HARTSHORNE STATES IN PERSPECTIVE ON THE NATURE OF GEOGRAPHY (1959), HOWEVER THERE IS A HISTORICAL PROBLEM WITH THE CONCEPT OF LANDSCAPE IN GERMAN ETYMOLOGY LANDSCHAFT - WHICH, ALTHOUGH IN ENGLISH TRANSLATIONS TAKE ON THE WORD LANDSCAPE, BOTH WORDS HAVE DISTINCT MEANINGS. THE PRESENT ARTICLE, THEREFORE, AIMS TO REOPEN DISCUSSIONS REGARDING THESE FUNDAMENTAL DIFFERENCES, WHICH ARE THE REASON FOR SOME MISCONCEPTION, ESPECIALLY WHEN IT COMES TO THE PORTUGUESE LANGUAGE, WHEN THE GERMAN TERM WAS NOT USUALLY TRANSLATED FROM THE ORIGINAL, BUT FROM ITS ENGLISH AND FRENCH VERSIONS. HAVING THIS INITIAL QUESTION IN MIND, THE PRELIMINARILY PURPOSE IS TO ESTABLISH SOME DIFFERENCES BETWEEN THE ENGLISH LANDSCAPE AND THE GERMAN LANDSCHAFT IN THE VIEW OF THE PHILOSOPHICAL SCIENTIFIC THINKING REGARDING THE 18TH AND FIRST HALF OF THE 19TH CENTURIES.
\end{abstract}

KEYWORDS: LANDSCAPE; LANDSCHAFT; NATIONAL STATE; ROMANTICISM.

\section{NOTAS PRELIMINARES SOBRE EL CONCEPTO DE PAISAJE: ENTRE EL LANDSCAPE INGLÉS Y EL LANDSCHAFT ALEMÁN}

RESUMEN: ES POSIBLE DAR FE DE UNA REANUDACIÓN RELATIVAMENTE RECIENTE DE LOS ESTUDIOS DE PAISAJE, ESPECIALMENTE EN GEOGRAFÍA CULTURAL. SIN EMBARGO, ADEMÁS DE LA IMPORTANCIA DE ESTA ÁREA DE LAS CIENCIAS GEOGRÁFICAS, EL PAISAJE FUE UNA VEZ UN CONCEPTO CLAVE PARA COMPRENDER LA NATURALEZA Y LA GEOGRAFÍA DEL HOMBRE. COMO SEÑALA RICHARD HARTSHORNE EN PERSPECTIVE ON THE NATURE OF GEOGRAPHY (1959), SIN EMBARGO, EXISTE UN PROBLEMA HISTÓRICO CON EL CONCEPTO DE PAISAJE EN LA ETIMOLOGÍA ALEMANA - LANDSCHAFT - QUE, AUNQUE EN LAS TRADUCCIONES INGLESAS ADOPTAN LA PALABRA LANDSCAPE, AMBOS TIENEN SIGNIFICADOS CLARAMENTE DISTINTO. EL PRESENTE ARTÍCULO, POR TANTO, BUSCA REABRIR LAS DISCUSIONES SOBRE ESTAS DIFERENCIAS FUNDAMENTALES, LO QUE ES EL MOTIVO DE CIERTO RUIDO, ESPECIALMENTE CUANDO SE TRATA DE LA LENGUA PORTUGUESA, CUANDO EL TÉRMINO ALEMÁN NO SE SUELE TRADUCIR DEL ORIGINAL, SINO DE SUS VERSIONES EN INGLÉS Y FRANCÉS. TENIENDO ESTA PREGUNTA INICIAL, EL OBJETIVO ES ESTABLECER DE FORMA PRELIMINAR ALGUNAS DIFERENCIAS ENTRE EL LANDSCAPE INGLÉS Y EL LANDSCHAFT ALEMÁN, EN VISTA DEL PENSAMIENTO CIENTÍFICO FILOSÓFICO REFERIDO A LOS SIGLOS XVIII Y PRIMERA MITAD DEL XIX.

PALABRAS CLAVE: PAISAJE; LANDSCHAFT; ESTADO NACIONAL; ROMANTICISMO. 


\section{Considerações Iniciais}

Como é possível observar em Perspective on the Nature of Geography (HARTSHORNE, 1959), há um problema histórico com relação ao conceito de paisagem. Considerado conceito-chave para a Geografia alemã, o termo Landschaft abriu diversas discussões - e talvez não tantas como devesse, ao menos no Brasil - quanto à sua ambiguidade, razão pela qual os seus significados ainda permaneçam, em parte, obscuros, em especial com relação à tradução do termo alemão para a língua inglesa. Assim, por muitos, Landschaft e landscape foram tratados como sinônimos de uma só paisagem quando de sua expressão na língua portuguesa - condição acentuada pela tradução da tradução, do alemão para o inglês, e posteriormente para o português.

Deste modo, nosso desafio se instaura na hercúlea tarefa de re-associar seus significados e permitir uma melhor compreensão do que tanto um, na língua alemã, quanto o outro, na língua inglesa guardam de distinção, tensão ou até mesmo de distensão. A confusão foi instaurada "quando o termo alemão, que pode significar scene ou region foi introduzida na geografia americana e britânica simplesmente como landscape" (HARTSHORNE, 1959, p. 3) - e há de se dizer o mesmo quanto às traduções brasileiras do francês, uma vez o termo francês paysage guarda mais proximidades com o inglês do que com o alemão. Antes de qualquer abordagem sobre as diferenças, há de se atentar para algumas questões.

A institucionalização da Geografia como ciência moderna não acompanha exatamente a origem da percepção dos fenômenos geográficos. Os fenômenos sempre existiram e deles a curiosidade em reconhecê-los. Bem é lembrado por Sauer (1998 [1925]) ao dizer que foi a experiência do homem com os fenômenos, não a pesquisa do especialista, que estabeleceu as subdivisões do conhecimento. Há uma curiosidade primordial que preconiza o estudo de determinado fenômeno, o choque do ser com aquilo que lhe vai de encontro, diferentemente do especialista, que vai ao encontro do fenômeno. Uma curiosidade comum acerca de determinado assunto abre caminho para a um direcionamento científico e, assim, cada forma de conhecimento inclina o seu olhar a uma maneira diferente de perceber a natureza.

O fenômeno das áreas e das paisagens vai ao encontro do ser que, naturalmente, deseja conhecê-los. Entretanto, cabe questionar: como esse desejo é posto em prática, como a razão atua sobre a percepção das paisagens?

Historicamente, o conceito de paisagem se metamorfoseou de acordo com os princípios de percepção da natureza de cada época e território ou conforme a construção 
social do pensamento percebia a paisagem enquanto um quid pro quo. É notório dizer, porém, que a paisagem está diretamente relacionada aos aspectos sensoriais do espaço geográfico. Como afirma Denis Cosgrove, “a paisagem, de fato, é uma maneira de ver, uma maneira de compor e harmonizar o mundo externo em uma cena, em uma unidade visual" (COSGROVE, 1998, p. 98). Enquanto uma maneira de ver é mister, portanto, compreender que o conceito de paisagem esteve presente ao longo da história através da iniciativa do direcionamento do olhar, aguçado que é pelos demais sentidos em suas funções.

Tendo como base o estudo da natureza como fundamental na mudança das percepções da paisagem, é substancial atestar a importância dos séculos XVIII e XIX no que tange à consolidação da paisagem como um conceito das ciências modernas. Ainda que seja possível averiguar as tendências da assimilação e do contato com a natureza em período anterior à sua percepção nos séculos mencionados - como nas narrativas geracionais -, a paisagem sofre grandes mudanças à luz das ciências modernas e de movimentos reativos que surgem nesse período, com atenção especial ao racionalismo iluminista - e até mesmo um resgate às ideias classicistas - e o romantismo alemão.

À guisa de um objetivo geral para o artigo em tela, o verbo verificar seria o mais apropriado no sentido de buscar simetrias e assimetrias entre a Landschaft alemã e a landscape inglesa. Especificamente, a versão francesa, paysage - e até as versões em outras línguas -, aqui e ali transborda para indicar as verossimilhanças mais afinadas com a versão inglesa do vocábulo paisagem trazido ao português. Acreditamos ser fundamental uma retomada das discussões no que concerne a essas diferenças que rodeiam os conceitos de paisagem em distintas línguas, sobretudo no que tange às suas traduções e até mesmo traduções das traduções. Comumente causam estranheza, por vezes conflitos, quanto à definição do que grosso modo aprendemos a chamar de paisagem, enquanto conceito de matiz geográfico, no Brasil. A questão que se põe, por seu turno, é catalizadora para o entendimento de como os ruídos nas traduções atuaram tal qual palimpsesto a construir o conceito-chave de paisagem na Geografia brasileira, mesmo que com prejuízo a depender do uso efetivo do conceito. Metodologicamente, a revisão de literatura, ainda que de forma preliminar, possibilita marcar algumas diferenças entre a Landschaft e a landscape, tomando como partido o pensamento em vigor à época. 


\section{A Landscape}

No entendimento do norte-americano J. B. Jackson (1989), a origem do vocábulo landscape, associa duas partículas da língua inglesa: land, com um significado que pode ir para além da concepção de localidade, mas também com compreensão similar nas línguas latinas, ou seja, como terra agrícola - o mesmo autor chama a atenção para o momento da introdução do termo na Grã-Bretanha, no Século V, e seu desígnio correlato original, como estando associado ao uso, ao ordenamento da terra. A landscape, portanto, guardará proximidade com o vocábulo latino pagus, do mesmo período medieval, que era identificado como uma determinada porção de terras, sendo a base de seu sucessor, o vocábulo paisagem, cuja origem está no italiano paesaggio e seu correspondente no francês, paysage. A este raciocínio, acrescenta-se:

o vocábulo francês paysan (ou paysanne) traduz-se por camponês, por exemplo. Há elementos, tanto nas línguas de origem latina quanto nas de origem anglo-saxônica, capazes de referendar a ideia de paisagem enquanto fruto da ação humana dos que vivem na terra e sobre a terra, sempre agrícola. Esta é a base do pensamento de Jackson (1989), ainda mais quando acrescenta a raiz de compreensão do vocábulo scape com a idéia de sistema [ou organização] (FERNANDES, 2006, p. 43).

Entretanto, a origem anglo-saxônica do vocábulo, que remonta ao Século V, se imbrica com uma diversidade de origens na composição do povo da grande Bretanha, bem como na constituição do anglo-saxão como língua, a bem da verdade, o chamado inglês antigo, que está ancorado na expressão alemã Völkerwanderung (POHL, 2013). Tal expressão corresponde à longa série de migrações ditas bárbaras que incidem por diferentes territórios de toda a Europa antes sob o comando do Império Romano, e que, especificamente, levam à Ilha da Grã-Bretanha povos germânicos, anglos e saxões em destaque, convergindo na transmutação da língua entre o latim romano e o falar dos povos pejorativamente chamados de invasores. Em verdade,

uma população bárbara e imigrante se estabeleceu desde uma data relativamente remota no século quinto como uma força politicamente poderosa no leste da Grã-Bretanha. Isso estimulou um processo de mudança social e cultural - em termos de linguagem e cultura material, pelo menos - no restante das terras baixas. Combinados, imigração e aculturação foram os processos pelos quais a Grã-Bretanha sub-romana foi transformada na Inglaterra anglo-saxônica (HIGHAM, 2004, p. 16).

Ora, o que se postula é que a raiz latina do vocábulo pagus presente na Brittannia de dominação romana contaminou o entendimento da landscape inglesa, mesmo esta 
conservando gramaticalmente maior proximidade linguística com a Landschaft alemã. Se vamos às avaliações da transcrição do Seminário de Arte (The Art Seminar) ${ }^{2}$ - as avaliações correspondem à seção 4 e o Seminário corresponde à seção 3 do livro Landscape Theory (Teoria da Paisagem), editado por Rachel DeLue e James Elkins (2008) - temos a interpretação de Kenneth R. Olwig (2008, p. 158) sobre a distinção entre "a 'paisagem real' ou paisagens reais" - The “Actual Landscape” or Actual Landscapes? -, que a ele suscita em relação a uma das discussões presentes no seminário. Na tentativa desse entendimento, o autor discorre sobre um comentário de Anne Whiston Spirn (DeLue; Elkins, 2008, p. 92) sobre a origem etimológica da landscape:

\begin{abstract}
se você olhar para as raízes da palavra paisagem em línguas nórdicas e germânicas, por exemplo, landskab em dinamarquês, Landschaft em alemão, ou landscipe no inglês antigo, você vê uma combinação de significados que associam um lugar e as pessoas que moram lá [morararam lá], no passado e no presente. Land significa tanto as características físicas de um lugar quanto sua população. Skabe e schaffen significam "moldar" e os sufixos -skab e -schaft, como no inglês -ship, também significam associação, parceria. Há uma noção, embutida na palavra original, de uma formação mútua de pessoas e lugares [people and place]: as pessoas moldam a land, e a land molda as pessoas. Mas o Oxford English Dictionary afirma que a landscape vem de um termo da pintura holandesa, landskip, e foi importado para o inglês no século XVII. Não é bem assim! Porque é que o os significados da palavra paisagem em inglês antigo se perdem?
\end{abstract}

Ao responder à pergunta de Anne Whiston Spirn exposta acima, Olwig (2008) aponta para o já referido Oxford English Dictionary [OED], publicado a partir de 1884, como fonte da homogeneização do vocábulo landscape na língua inglesa padrão que buscava se estabelecer no Século XIX: "os editores do OED viram discordância entre landscipe, entendido como lugar em particular, e a ideia cênica da landscape como forma de representação pictórica do espaço e, portanto, decidiu eliminar a landscipe da contemporânea definição da landscape" (OLWIG, 2008, p. 160). Por outro lado, a landscape que passou a contar com um único significado específico construído pelo OED não exatamente era vista assim em outros dicionários mais antigos, como o Johnson's Dictionary, de 1755; e tão pouco o entendimento neerlandês sobre a sua landskip poderia

\footnotetext{
${ }^{2}$ Este seminário foi realizado em 17 de junho de 2006, no Burren College of Art, Ballyvaughan, Irlanda. Os participantes foram: Denis E. Cosgrove (Universidade da Califórnia, em Los Angeles), Rachael Ziady DeLue (Princeton University), Jessica Dubow (University of Sheffield), James Elkins (University College Cork / School of Art Institute of Chicago), Michael Gaudio (Universidade de Minnesota), David Hays (Universidade de Illinois em Urbana-Champaign), Róisín Kennedy (National Gallery of Ireland, Dublin), Michael Newman (School of the Art Institute of Chicago), Rebecca Solnit (acadêmica independente), Anne Whiston Spirn (Instituto de Tecnologia de Massachusetts), Minna Törmä (Universidade de Helsinque), Jacob Wamberg (Universidade de Aarhus, Dinamarca).
} 
ter aproximação com a definição da landscape que o OED foi nesta buscar (OLWIG, 2008).

Em diálogo no mesmo seminário, David Hays e Anne Whiston Spirn (DeLue; Elkins, 2008, p. 93) apontam para tais contradições na consideração equivocada da landscape pelo OED. David Hays diz: "Anne, esses mal-entendidos da palavra paisagem são na verdade, uma dupla etimologia falsa. Quando as pessoas definem paisagem, eles geralmente tomam -scape como -scope, como se pertencesse à visão. Mas não é assim”. Em retorno, Anne Whiston Spirn complementa: "em inglês antigo, implicava tanto uma associação com um lugar e uma modelagem física. Mais tarde, cresceu em seu sentido atual de vista, uma vista panorâmica”. Isto nos leva ao vocábulo -scope como, no entendimento de James Elkins (DeLue; Elkins, 2008, pp. 93-94) de uma paisagem enquanto "objeto visto, como algo construído a partir de representações do espaço e tempo". A esse respeito, OLWIG (2008), ao fazer sua avaliação crítica sobre o diálogo a envolver as partículas -scape e -scope, depreende que

na medida em que os primeiros pintores de paisagem neerlandeses pintaram regiões (no sentido de país ou terra [country ou land]) como vistas em perpectiva, eles estavam visualmente envolvidos com a ideia representada pelo sufixo -scape em um momento em que -scape não significava -escope, mas algo bem diferente. $\mathrm{O}$ artista neerlandês, de pé em uma colina elevada (ou fingindo estar), ganha uma ampla perspectiva sobre o país abaixo, que dá uma visão geral do caráter, ou forma, da terra que não seria visível de perto. Scape passou a ser identificado com -scope porque a visão distante fornecia um maneira de abstrair a qualidade abstrata de uma região, país ou terra [ land's -scape] (OLWIG, 2008, pp. 163-164).

Para Denis Cosgrove (2004, p. 57), o mais importante era examinar "as implicações desses desenvolvimentos para o conceito de paisagem e seu significado revivido e uso dentro da Geografia e além”. De fato, no mesmo artigo, o autor enfatiza a importância dos diferentes significados acumulados ou modificados entre os vocábulos Landschaft (alemão) e landscape (inglês) como algo mais do que puramente de caráter filológico - "as migrações de significado que Landschaft/landscape experimentou” acabou por torná-lo "particularmente adequado para formas contemporâneas de pensar sobre espaço e reconectando o estudo geográfico às preocupações atuais das humanidades com cultura, identidade e significado" (COSGROVE, 2004, p. 58).

Em trabalho anterior, o mesmo Denis Cosgrove (1985) já havia indicado que o conceito de paisagem, em sua forma inglesa landscape - originado a partir da palavra alemã Landschaft - havia ressurgido no período renascentista, entre os séculos XV e 
início do XVI juntamente ao avanço do conhecimento científico, onde é dedicado à razão um novo patamar na busca pelo conhecimento. Nesse momento, as técnicas de perspectiva iniciam o processo de laicização da paisagem (CANTERO, 2006), promovendo um antropocentrismo em sua representação. Quando não a figura do homem divinificada e matematicamente composta, a paisagem (landscape) demonstrava a visão do homem para com determinado território. O conceito de paisagem, portanto, em sua concepção primeira, estava diretamente relacionado ao do território, como uma maneira de "estabelecer e divulgar uma imagem teatral do território" (BESSÉ, 2014, p. 113), promovendo uma visão cenográfica. A ligação profunda entre os dois termos é fortalecida quando se coloca a paisagem como o estado estático ideal do território, ou mesmo o próprio território.

O princípio racionalizante renascentista no que concerne ao significado da palavra landscape ganha contornos políticos, portanto, vinculados à formação dos Estados modernos. A necessidade de re-conhecer a paisagem passava por tornar concreto o território de determinado Estado em viés de unificação, tornar um conceito abstrato como o território nacional em algo palpável para os sentidos, numa maneira de olhar. Como maneira de olhar, além de e através das técnicas de perspectiva, preconizase nesse momento a representação da paisagem como uma medida calculável. No mais, a partir da perspectiva foi possível consolidar a representação de uma paisagem vista do alto, aérea, fornecendo ao conceito de paisagem novas possibilidades. Sob a influência desse período classicista provindo da Renascença, “a paisagem moderna foi integrada, de um lado, à imagística militar e, de outro, à imagística política de tipo nacionalista, particularmente no século XIX” (BESSE, 2014, p. 107).

O conceito, em vista do supramencionado, ganha forma em virtude de uma racionalização do que é observado através de uma percepção político-militar. A vista aérea compreenderia um olhar intimista do general para com o território de batalha, ou melhor, para com o seu território. Essa imagística militar corrobora intensamente com a proposição nacionalista da formação dos Estados que viriam surgir. A imagem representada, importante dizer - e a que se compreende como funcional para os fins militares -, é a paisagem do general que contempla minuciosamente os elementos presentes em um grande sistema da paisagem, não aquela que subjetivamente é percebida pelo combatente, vista de baixo. O que importa, portanto, é tornar concreto, através dos aspectos visíveis, o território e, por isso, não à toa a prerrogativa de Yves Lacoste (2011 [1976]) se torna verdadeira: a Geografia, isto serve em primeiro lugar para fazer a 
guerra. Nesse sentido, quando se diz "A Geografia”, é possível entender como a percepção das paisagens, em um primeiro momento, serviram para fins estratégicos militares com o intuito racional de formação dos Estados nacionais modernos. Mais que isso, porém, a observação das paisagens é, antes de tudo, um espaço submetido a uma vontade de controle, visual e estratégico. A ratificar tal pensamento, Jean-Marc Besse aponta:

a paisagem é, antes de tudo, um espaço submetido a uma vontade de controle, visual e estratégico. Desde o século XVII pelo menos, a paisagem aparece, nos retratos dos chefes de guerra (generais ou monarcas), como um campo de ação que é observado do alto, em recuo (BESSE, 2014, p. 107).

Da premissa acima descrita há de se compreender que a paisagem não apenas esteve no radar das pautas nacionalistas como também era conceito-chave para a própria formação do Estado Nacional, pois passou a encarnar nela própria a identidade histórica e geográfica de uma nação. A landscape também fortalecia a história oficial, de personagens que desbravaram o território e conquistaram terras em nome de uma nação. Há uma construção de narrativas que vinculam heróis e solo pátrio ou convergem o apoio das massas com outras identidades, como aquelas vinculadas ao que a paisagem proporciona. Analisando a obra de Eric Hobsbawm, Nations and Nationalism since 1780: Programme, Myth, Reality (1990), o historiador português Carlos Maurício expõe o pensamento do primeiro sobre a criação das nações: "construídas essencialmente a partir de cima, não podiam ser compreendidas se não fossem tidas em conta as esperanças, as necessidades, os desejos e os interesses das pessoas comuns” (MAURÍCIO, 2012, p. 115).

Por outro lado, a composição cenográfica da paisagem promovida pelas técnicas de perspectiva, que acompanha e expressa o estabelecimento da concepção moderna de Estado como entidade nacional, eleva-se acima das preocupações locais. Tendo em vista o registro do surgimento do conceito, este esteve em viés de enaltecer o poder absoluto. Nessa perspectiva, a paisagem é a manifestação concreta do território tal como é visto sob o ponto de vista do Estado. Em assim sendo, destacamos o que descreve Maquiavel a Lorenzo de Médici:

nem quero que se repute presunção o fato de um homem de baixo e ínfimo estado discorrer e regular sobre o governo dos príncipes; pois os que desenham os contornos dos países se colocam na planície para considerar a natureza dos montes, e para considerar as planícies, ascendem aos montes, assim também para conhecer bem a natureza dos povos é necessário ser príncipe, e para conhecer a dos príncipes é necessário ser do povo (MAQUIAVEL, 2011 [1532], p. 15). 
Na passagem supracitada é possível perceber o que até aqui foi desenhado. Maquiavel, pensador político renascentista, escrevia com destino ao poder absoluto do príncipe e, através de sua escrita, demonstra uma pequena impressão de como o Estado passaria a perceber o seu território, através de uma análise estratégico-militar, que colocaria a visão como sentido máximo de tal percepção.

Assim como a landscape trazia essa visão racionalizante através das técnicas de perspectiva, a paysage, em francês, também outorgava à visão o sentido primeiro da percepção do território. Apesar de originado da palavra paysenne (camponês) - que concerne ao conceito uma ideia de paisagem "natural" ou rural - havia um princípio também racionalizante enviesado pela premissa do século das luzes ${ }^{3}$. Assim foi traçada a perspectiva do conceito para a formação dos Estados nacionais mais à frente, sob viés iluminista. Contudo, um novo movimento anti-racionalista, idealista, surgia na Alemanha acusando a chamada ditadura da razão, o romantismo.

\section{A Landschaft}

Evidentemente, o termo alemão não nasce após o romantismo ou mesmo em razão deste. Ao contrário, a potência da Landschafté ainda mais relevante no que se refere ao pensamento da época. Sua existência e profundidade estão intimamente relacionadas ao interesse cultural do alemão pela natureza, pelos mitos originais, pelos mistérios, as narrativas das florestas e das montanhas (SCHAMA, 1996) e pelos poderes originais do solo, conceitos que mais tarde dariam pulsão ao romantismo. Não à toa, Ratzel - que evidentemente não era um pensador romântico, mas alemão - discursa sobre os poderes da geografia física na formação de um território como forças que circundam e criam os limites de um espaço vital, onde há uma dimensão de pertencimento nas paisagens (MORAES, 1990). O geógrafo francês Élisée Reclus, por outro lado, reconhece que,

apesar de alguns desvios que ele tenha sofrido desde o começo da era histórica, esse amor sempre foi um dos traços distintivos das populações da Germânia, assim como o provam as lendas e as canções coletadas em tão grande número nas diversas regiões da Alemanha. Os descendentes desses teutões que habitavam as florestas profundas jamais ignoraram a beleza de seus bosques de carvalhos, faias ou abetos, de suas fontes brotando discretamente na relva dos prados ou sob as folhas mortas, de suas montanhas abauladas, todas rajadas de neve durante o inverno (RECLUS, 2010 [1866], pp. 56-57).

\footnotetext{
${ }^{3} \mathrm{O}$ conceito de paisagem, em francês, carregaria também influência das ciências modernas no contexto do Iluminismo, do Século XVIII. 
Na busca pela reinvenção da cultura, na criação de uma comunidade imaginada, os românticos carregam consigo um espírito explorador presente, por exemplo, em Johann Gottfried von Herder que "durante suas viagens traçou o plano de colecionar canções populares e outros documentos das culturas dos povos” (SAFRANSKI, 2010, p. 29), acabando por estimular que o mesmo fosse feito por outros pensadores de seu tempo. Evidentemente, as narrativas já estavam presentes e, grande parte delas, vinculadas ao solo e às paisagens, como apontado em Reclus (2010 [1866]), mas também se pode observar argumentação semelhante em Simon Schama (1996) - em sua obra, Paisagem e Memória, o autor dedica uma seção inteira para falar dos povos germânicos, onde constrói a narrativa antiga dos mesmos com relação à floresta.

Ao conceito de paisagem oriundo do alemão, portanto, serão incorporados os saberes provindos do movimento romântico em questão. Como característica, que será constantemente reconhecida nas paisagens representadas, o Romantismo irá promover um culto ao antigo, às tradições e o engrandecimento da natureza como espelho da alma humana (FREITAS; PERES; RAHY, 1999). Como dito, o movimento acaba por travar uma disputa contra a civilidade racional intelectualizada provinda da rigidez iluminista e sua representação estática de uma arte oficial neoclássica. Subjuga-se a razão e elevamse as potências do subjetivo, dando espaço para a representação da crise moral, espiritual e estética de um tempo que preconiza a matematização da natureza em detrimento da presença de seu espírito formador. O Romantismo, por assim dizer, impulsiona uma nova maneira de olhar a natureza e, consequentemente, a Landschaft.

Diferente já em sua etimologia e em seu significado, a palavra paisagem - como visto, em alemão, Landschaft - absorve outros sentidos que não aqueles apenas descritos pela ciência, mas que depois serão considerados por esta. Ao contrário do que estabelecia a racionalização política proposta pelo conceito em inglês, já em sua etimologia é possível compreender as diferenças - Land (terra; país) schaft (criar; produzir). A palavra é abordada sob a égide das ciências modernas, inicialmente por Humboldt, através de uma acepção naturalista em que descreve a paisagem por meio de uma acepção natural (rocha; relevo; clima; água; solo), visando uma compreensão do todo sistemático ${ }^{4}$. Os elementos

\footnotetext{
${ }^{4}$ Ver: $1^{\circ}$ Los precisos limites de la descripción física del mundo, como ciencia distinta. $2^{\circ}$ La rápida enumeración de la totalidad de los fenómenos naturales, bajo la forma de un cuadro general de la naturaleza. $3^{\circ}$. La influencia del mundo esterior sobre la imaginación y el sentimiento; influencia que ha dado en los tiempos modernos un poderoso impulso al estudio de las ciencias naturales, por la animada descripción de lejanas regiones, por la pintura de paisaje, siempre que caracterice la fisonomía de los vegetales, por las plantaciones ó la disposición de las formas vegetales exóticas en grupos que entre sí contrasten. $4^{\circ}$ La historia de la contemplación de la naturaleza, ó el desarrollo progresivo de la idea del ESPAÇO E CULTURA, UERJ, RJ, JUL./DEZ DE 2020, N. 48, P. 158-177 http://www.e-publicacoes.uerj.br/index.php/espacoecultura/
} 
individualizados na análise deveriam estar de acordo com uma ação que constatasse a sua dinâmica com o todo, evitando um estudo individualizado e impessoal - a ideia humboldtiana daria embasamento ao conceito de Geossistema, onde a paisagem possui uma formação sistêmica (RODRIGUEZ; SILVA, 2002).

Contudo, é importante que se compreenda a essência do pensamento humboldtiano. Evidentemente, não se trata de um autor romântico. Alexander von Humboldt fora considerado um dos maiores cientistas de seu tempo e, em sua abordagem, surge um método comparativo de vigor altamente racionalista sob a égide dos avanços modernos nas ciências propiciados pelo iluminismo ${ }^{5}$. Racionalista por sua natureza científica, o autor, porém, carrega profunda influência do movimento romântico em vigor no século XIX - assim como esteve próximo da epistemologia kantiana, esteve junto ao vigor romântico de Goethe, seu amigo pessoal (WULF, 2016) - entregando ao conceito científico de paisagem aquilo que popularmente já era percebido, um espírito, um prazer que provem da contemplação, "prazer que é em primeiro lugar, uma impressão estética independente do conhecimento dos fenômenos" (CAPEL, 1988, p. 34).

A síntese proposta por Immanuel Kant entre o conhecimento empírico e racional (Kant, $2001[1781]$ ) seria sentida na obra de Humboldt posteriormente. O conhecimento, dessa forma, só poderia ser dado através da experiência vivida e sua posterior racionalização. Indo além, a coexistência de movimentos tão díspares no século XIX - as influentes ideias provenientes do que o iluminismo havia deixado e a reação romântica - proporcionou a inter-relação entre o modo de pensar racionalista e experiências estéticas provenientes de uma forma poética, estética, de olhar o mundo. Essa coexistência de padrões supostamente díspares permitiu o surgimento de uma nova relação do homem com o solo, quando não mais uma lógica exclusivamente matemática mediria e dissiparia as possibilidades da natureza, e onde as relações humanas se uniriam com o belo.

Dessa visão que começa a olhar a natureza não mais como um receptáculo de seres autômatos, destinados ao uso indiscriminado do homem, surge a naturgemalde"um termo alemão intraduzível que pode significar 'pintura da natureza', mas que também implica uma ideia de unidade ou todo” (WULF, 2016, p. 139) -, na qual cada ser

Cosmos, según la exposición de los hechos históricos y geográficos que nos han llevado á descubrir el enlace de los fenómenos (HUMBOLDT,1875. p. 52-53).

${ }^{5}$ Humboldt, inclusive, vivera muitos anos na França sob o pretex to de lá estar perto de onde pulsava o vigor científico nos séculos XVIII e XIX. Apesar de manter cargos na corte prussiana e conviver com as chantagens e aborrecimentos de seu irmão Willhelm von Humboldt, o naturalista não escondia sua preferência pela França, voltando para Berlim apenas quando obrigado (WULF, 2016). 
fazia parte de uma rede complexa e interligada, mas que também apontava para um espírito que não seria possível ser encontrado nos números. Não à toa um dos seus principais trabalhos é intitulado Quadros da Natureza (1952-53[1808]), seu favorito, e o primeiro em que imprime uma narrativa expressamente poética (WULF, 2016).

Como já dito, Humboldt não era um pensador romântico, mas suas ideias foram lapidadas por esse espírito próprio de sua época. Mais que isso, apesar e por ter sido um dos mais influentes cientistas de seu tempo, não estava sozinho nessa forma de pensar. Como afirmou Glacken (1999, p. 16), ao falar do período que compreende o final do século XVIII e primeira metade do século XIX " "não conheço nenhum outro período em que essas reações subjetivas, emocionais e estéticas ao mundo natural estivessem tão intimamente ligadas à pintura de paisagem", justamente no momento em que o movimento romântico ganha força e, com sua potência sensitiva, influencia inclusive muitos cientistas naturalistas e artistas - não apenas românticos - fazendo surgir uma nova forma de expressão.

As reações emocionais e estéticas com relação à paisagem não surgiriam apenas de artistas plásticos como Caspar David Friedrich - o qual negava o uso de técnicas regradas que buscavam emular a natureza como uma ordem matemática e dela retirar seu espírito (MATTOS, 2008) - e seu famoso quadro Der Wanderer über dem Nebelmeer (O Viajante sobre o mar de névoa, 1817 - vide a figura 1), mas também em obras que se destinavam a uma finalidade sistematizante - assim como Humboldt construiu sua ideia de natureza -, como The heart of the Andes (O Coração dos Andes, 1859 - vide a figura 2), de Frederic Edwin Church que, porém, como já designa seu título, intenta estabelecer uma ordem de espírito à natureza. 


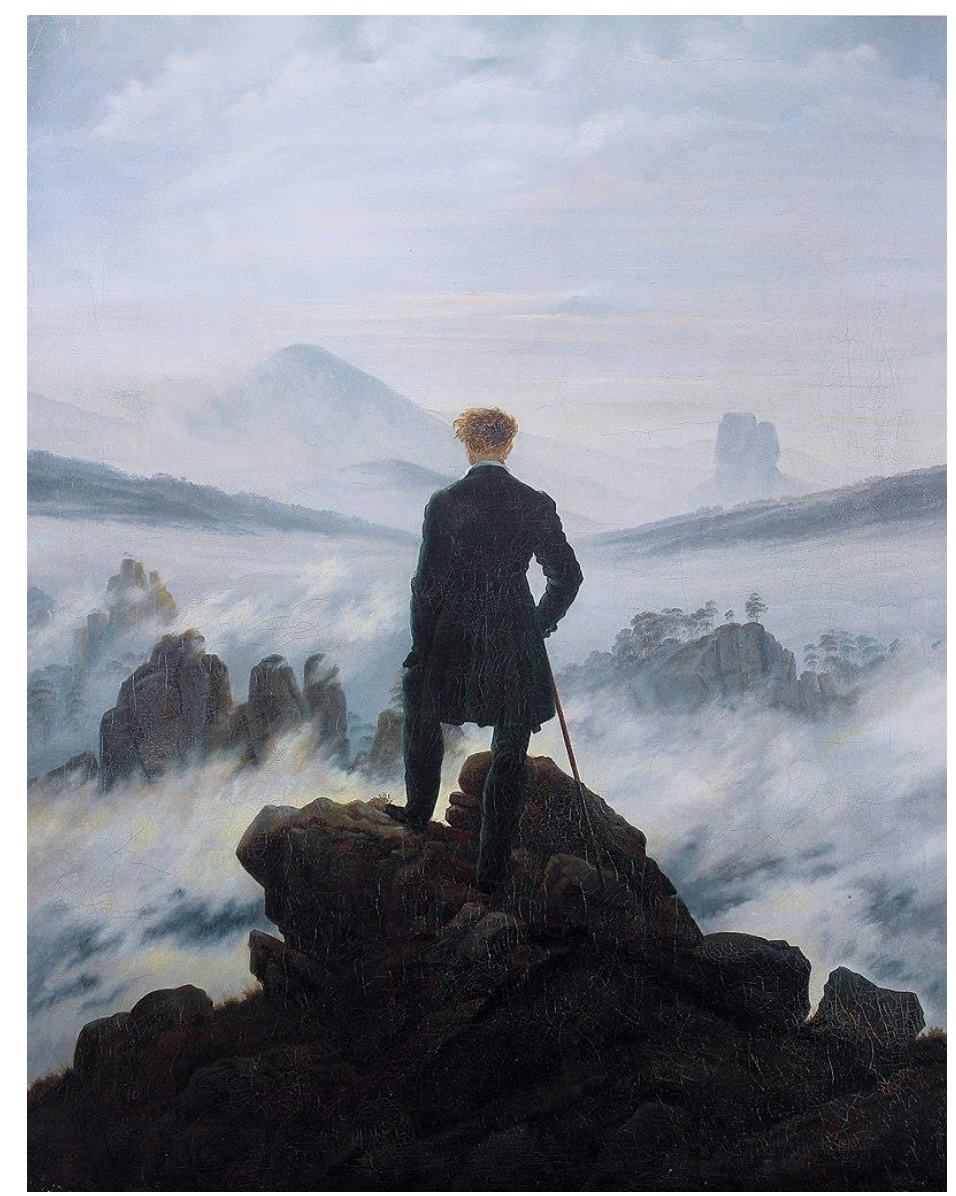

Figura 1: Der Wanderer über dem Nebelmeer (O Viajante sobre o mar de névoa), de Caspar D. Friedrich. Fonte: Domínio Público, circa 1817.

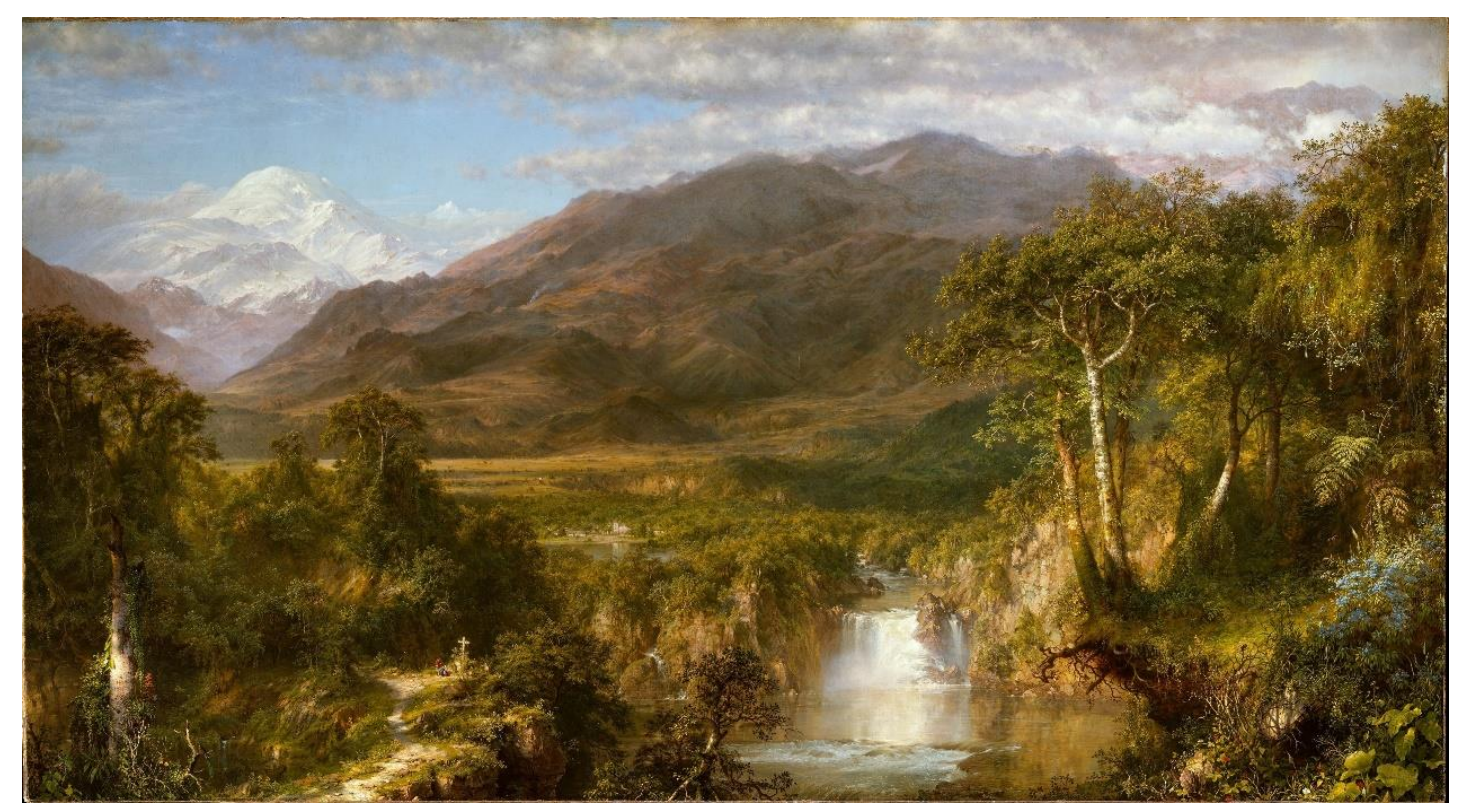

Figura 2: The heart of the Andes (O Coração dos Andes), de Frederic E. Church. Fonte: Domínio Público, 1859 
Carl Sauer diz que "a literatura da geografia em termos de corologia começa com as sagas e os mitos antigos, lembrados em relação ao sentido do lugar" (SAUER, 1998 [1925], p. 15), o que corrobora com a ideia de que o sentido de Landschaft, apesar de cientificamente aproveitado, absorve dos mitos originários a maneira de ver o mundo. É possível observar tal ímpeto de Humboldt ao dizer que:

a tentativa de desfazer em seus diversos elementos a magia do mundo físico é uma grande imprudência; porque a grande característica de uma Landschaft, e toda cena imponente da natureza, depende da simultaneidade das ideias e sentimentos que agitam o observador. O poder da natureza se revela, por dizer assim, na conexão das impressões, na unidade de emoções e efeitos que se produzem em certo modo uma única vez (HUMBOLDT, 1875, p, 9).

A forte ligação da Landschaft com os mitos originais está diretamente relacionada à sua proximidade com os costumes, da paisagem como um lugar de origem. Assim, para além das proposições realizadas pela landscape para a formação dos estados nacionais, a Landschaft propõe uma visão de pátria, como local de pertencimento orgânico, dos modos de vida. Dóra Drexler assim diferencia as noções de paisagem nas línguas aqui abordadas:

a principal diferença ocorre no desenvolvimento da ideia de paisagem nos estados alemães, comparada à Inglaterra e França, por volta de 1800, durante o chamado contrailuminismo. Um antigo elo com a terra e suas tradições locais (isto é, não universal) foi reestabelecido no conceito de paisagem alemã - capturada pela antiga palavra Landschaft. Landschaft se tornou carregada de sentidos visuais e estéticos, e foi percebida e apreciada como tradicional área rural e seus cenários pré-industriais e pré-modernos (DREXLER, 2013, p. 91).

Algumas lições podem ser tiradas, portanto, da citação. O movimento contrailuminista assinalado, o Romantismo, propunha o mundo como uma obra de arte, uma visão estética do real, onde os sentidos pudessem aflorar, dando lugar a um espírito dos lugares (Ortgeist). Landschaft - como produzir, como criar terra -, portanto, reestabelece um elo de uso da terra com técnicas propriamente locais de ordem tradicional. Não há nada mais romântico que o aflorar do espírito tradicional que insurge do solo, dos lugares, algo que fez com que Johann Gottfried von Herder seguisse expedições em busca dos poderes originais do solo, colecionando canções, poesia, danças e paisagens dos lugares (SAFRANSKI, 2010).

Como é possível perceber, essa nova perspectiva de análise concederia um novo vigor aos nacionalismos. Agora, para além da visão aérea do Estado, o povo estaria, enquanto unidade, pertencente e direcionando o olhar da paisagem que construiriam nos 
seus costumes tradicionais - Landschaft, com o significado de produzir a própria terra. Mais que isso, porém, como afirma Jean-Marc Besse (2014), a Landschaft é um espelho jurídico de sua população, daquela que a abriga, de uma comunidade disposta a defender e preservar seus costumes e tradições de manipulação da paisagem a qual pertencem. Não à toa a palavra Landschaft era também usada para designar região, "significava uma unidade de ocupação humana, uma jurisdição, tanto quanto um objeto passível de admiração” (SCHAMA, 1996, p. 10). Em outras palavras, Jean-Marc Besse irá afirmar que o território e, portanto, a paisagem como sua representação sensorial, "é o espelho do direito e seu prolongamento, e não o inverso" (BESSE, 2014, p. 109). Dito isso, os elementos individualizados que constituirão a noção totalizante de povo, pertencentes a determinada paisagem, são parte do processo hegemônico de pertencimento ao solo, que deriva de uma abordagem legal. Introduzindo uma nova perspectiva de escala, ao absorver tais ideias com viés político estatal, a comunidade local torna-se unidade do povo. Ainda segundo Besse,

a Landschaft é uma entidade político-jurídica de um tipo particular: a) é baseada num conjunto de direitos costumeiros (que foram quase todos recolhidos e transcritos no século XVI); b) a população da Landschaft soube conservar uma independência política, um relativo poder de autodeterminação em relação a divisões políticas e administrativas mais amplas, tanto de tipo feudal quanto monárquico. Não é raro ler que uma Landschaft foi ao tribunal da região fazer valer seus direitos, defender seus costumes: o que quer dizer, no caso, que a Landschaft não é, no espírito dos que transcrevem o acontecimento, nada diferente de um conjunto de cidadãos organizados em corpo político (BESSE, 2014, p. 110).

Landschaft, como dito, absorve uma concepção de paisagem como parte do local e que absorve uma jurisdição. Essa característica primordial, porém, pelo menos a princípio, expressa no imaginário popular uma estética de ordem natural, distante das técnicas de ordem urbana. A paisagem rural é representada e, junto com ela, o homem do campo como representação ideal de modo de vida. O romantismo, como foi observado, se apresenta como um movimento reativo ao racionalismo - sobretudo iluminista, mas também a outros que entregam leis matemáticas na composição das paisagens, como o próprio renascimento - irá entrar em conflito com o pujante mundo industrial e urbano que se anunciava, espraiando-se por toda a Europa de maneira acelerada. Em razão disso "é inseparável dessa reação o movimento de revalorização da natureza e do mundo rural" (DUARTE, 2004, p. 7) e, dessa aproximação, a criação de um sentido profundo e mítico do homem do campo e sua paisagem. 
Assim como na landscape, que continha uma teleologia bem ensaiada, ou seja, uma finalidade direcionada para a necessidade e consolidação dos Estados nacionais, a Landschaft arraigou fins semelhantes. Contudo, desloca-se o eu, aquele que irá vislumbrar a paisagem e com isso, apesar de ser possível averiguar fins semelhantes, modificam-se os meios. Partindo das localidades na busca pelas especificidades costumeiras, da cultura, dos saberes populares, Landschaft está a par "do que poderíamos chamar, na linguagem política contemporânea, de país ou território” (BESSE, 2014, p. 110), onde a representação visual dos fenômenos não parte de uma cenografia puramente racional, mas de uma comunidade política de base organizada pelos costumes, uma representação que resgata os valores estéticos que buscam, justamente, a natureza de um povo - a essência, um fenômeno, algo mais profundo. O romantismo, como é possível averiguar em Berlin (2013 [1965]), em sua reação ao iluminismo proferia a ideia de que as leis universais tiravam das coisas a sua natureza profunda, reduzindo suas possibilidades, trazendo-as para a superfície. Portanto, a profundidade é um conceito romântico, onde as possibilidades não podem ser esgotadas - é, posto, onde a Landschaft se circunscreve.

Essa nova forma de pensar, de experimentar o mundo através da descoberta de novas culturas e pô-las em prática de maneira oficial provocaria um processo de territorialização orgânica a partir da identidade natural com o espaço. Língua, etnia, paisagem, costumes, cultura, religião, todos símbolos de uma relação dinâmica com o solo que, ao serem catalogados e oficializados dariam o sentido de pertencimento. Relega-se, na visão romântica de Landschaft, a perspectiva do Estado para com seu território, retirando do general o eu, entregando ao "combatente" o ponto de vista, àqueles que costumeiramente vivem o local e que buscam preservar suas tradições.

\section{Considerações Finais}

O artigo em tela, como já dito inicialmente, não busca finalizar o tema, bem como esforça-se por apresentar um estudo preliminar sobre o estudo de paisagem e sua conceptualização a partir de duas etimologias diferentes, a de língua inglesa e a de língua alemã. Para tal, foi possível observar que os conceitos de landscape e Landschaft possuem diferenças cruciais que se demarcaram no tempo e no espaço através da dinâmica de mobilidade populacional na Europa Medieval, na confluência de povos e culturas superpostos e do modo pelo qual vocábulo e conceito constituíram-se em entendimentos 
que podem ser avaliados como divergentes, e com sentidos mais específicos a depender de onde se constituíram.

Landscape e Landschaft dizem sobre a paisagem enquanto conceito que no Brasil se conhece. Contudo, a tradução que se faz dos distintos vocábulos, sem o aprofundamento devido remete a uma única paisagem, onde um discurso parece prevalecer, mas que em sua essência afeta a percepção mais correta de seus significados - e isso se aproxima mais da landscape inglesa e da paysage francesa. A Landschaft alemã - fruto de uma riquíssima confluência entre as ciências modernas e uma pujante filosofia (romantismo) que buscava nos poderes originais do solo uma entidade poética nas paisagens, um espírito, algo como o Gênio Ródio de Humboldt (1952-53) - não é a mesma que a landscape inglesa, que mesmo mais próxima da paysage francesa se expressa em peculiaridades diferentes, algo que se espera defender em um futuro trabalho.

\section{REFERÊNCIAS BIBLIOGRÁFICAS}

BERLIN, Isaiah. The Roots of Romanticism. New Jersey: Princeton University Press, 2013 [1965].

BESSE, Jean-Marc. O Gosto do Mundo: Exercícios de Paisagem. Rio de Janeiro: EdUERJ, 2014.

CANTERO, Nicolas Ortega. Entre la Explicacion y la Geografia Moderna. In: FIZ, Simón Marchán; MADERUELO, Javier. Paysage y Pensamiento. Espanha: Abada Editores, 2006.

CAPEL, Horacio. Filosofía y ciencia en la Geografía contemporânea - una introducción a la Geografía. Barcelona: Huropesa, 1988.

CHURCH, Frederic E. (Artista). (1859). The heart of the Andes (O Coração dos Andes) [pintura a óleo]. Metropolitan Museum of Art, Nova Iorque, EEUU. Disponível em: https://commons.wikimedia.org/wiki/File:Church_Heart_of_the_Andes.jpg. Acesso em: 11 dez. 2020 [Domínio Público].

COSGROVE, Denis. Prospect, Perspective and the Evolution of Landscape Idea. In: Transactions of the Institute of British Geographers, News Series, Londres, Vol. 10, n. 1, pp. 45-62, $1985 . \quad$ Disponível em: https://rgs-ibg.onlinelibrary.wiley.com/pbassets/assets/14755661/Cosgrove-1510051530000.pdf. Acesso em: 11 dez. 2020.

COSGROVE, Denis. A Geografia Está em Toda Parte: Cultura e Simbolismo nas Paisagens Humanas. In: CORREA, Roberto \& ROSENDAHL, Zeny. Paisagem, Tempo e Cultura. Rio de Janeiro: EdUERJ, 1998.

COSGROVE, Denis. Landscape and Landschaft - Lecture delivered at the "Spatial Turn in History” Symposium. In: German Historical Institute Bulletin, Whashington, DC, n. 35, pp. 57-71, 2004). Disponível em: https://legacy.ghidc.org/fileadmin/user_upload/GHI_Washington/Publications/Bulletin35/35.57.pdf. Acesso em: 11 dez. 2020. 
DREXLER, Dóra. Landscape, Paysage, Landschaft, Táj: The cultural background of landscape perceptions in England, France, Germany and Hungary. In: Journal of Ecological Anthropology. Tampa, FL, vol. 16, n. 1, pp. 85-96, 2013. Disponível em: https://scholarcommons.usf.edu/jea/vol16/iss1/7/. Acesso em: 11 dez. 2020.

DUARTE, Luis Fernando Dias. A Pulsão Romântica e as Ciências Humanas no Ocidente. In: Revista Brasileira de Ciências Sociais, São Paulo, v. 19, n. 55, pp. 05-19, jun. 2004. Disponível em: https://www.scielo.br/pdf/rbcsoc/v19n55/a01v1955.pdf. Acesso em: 11 dez. 2020.

DeLUE, Rachael; ELKINS, James. Landscape Theory - The Art Seminar, Volume VI. New Yord \& London: Routledge, 2008.

FERnANDES, Ulisses S. A Natureza Monumental do Copacabana Palace Hotel - A Antevisão de Uma Paisagem. 2006. 200 f. Dissertação (Mestrado em Geografia) - Instituto de Geociências, Universidade do Estado do Rio de Janeiro, 2006.

FREITAS, Inês Aguiar; PERES, Waldir Rugero; RAHY, Ione Salomão. A Janela de Hitler. In: Revista GeoUERJ, Rio de Janeiro, n. 6, pp. 29-36, 1999.

FRIEDRICH, Caspar D. (Artista). (circa 1817). Der Wanderer über dem Nebelmeer (O Viajante sobre o mar de névoa) [pintura a óleo]. Hamburger Kunsthalle, Hamburgo, Alemanha. Disponível em: https://commons.wikimedia.org/wiki/File:Caspar_David_Friedrich__Wanderer_above_the_sea_of_fog.jpg. Acesso em: 11 dez. 2020 [Domínio Público].

GLACKEN, Clarence. Reflections on the History of Western Attitudes to Nature. In: BUTTIMER, Anne \& WALLIN, Luke. Nature and Identity in Cross-Cultural Perspective. Dodrecht, Boston, London: Kluwer, 1999.

HARTSHORNE, Richard. Perspective on the Nature of Geography. Chicago: The Association of American Geographers, 1959.

HIGHAM, Nick. From sub-Roman Britain to Anglo-Saxon England: Debating the Insular Dark Ages. In: History Compass, Hoboken, NJ, n. 2, BI 085, 2004, pp. 01-29. Disponível em: https://onlinelibrary.wiley.com/doi/epdf/10.1111/j.1478-0542.2004.00085.x. Acesso em: 05 dez. 2020.

HOBSBAWM, Eric. Nations and Nationalism since 1780 - Programme, Myth, Reality. Cambridge: Cambridge University Press, 1990.

HUMBOLDT, Alexander von. Quadros da Natureza - volumes I \& II. São Paulo: Gráfica Editora Brasileira, 1952-53 [1808].

HUMBOLDT, Alexander von. Cosmos. Tomos 1 y 2. Eduardo Perié Editor: Bélgica y Sevilla, $1875 . \quad$ Disponível em: http://www2.fct.unesp.br/docentes/geo/bernardo/BIBLIOGRAFIA\%20DISCIPLINAS\%20 POSGRADUACAO/ALEXANDER\%20VON\%20HUMBOLT/Humboldt,\%20A.\%20Cosmos.pdf. Acesso em: 11 dez. 2020.

JACKSON, J B. The Vernacular Landscape. In: PENNING-ROWSELL, Edmund C.; LOWENTHAL, David. Landscape: Meanings and Values. London: Unwin Hyman, 1989. pp. 6581.

KANT, Immanuel. Crítica da Razão Pura. Lisboa: Fundação Calouste Gulbenkian, 2001 [1781].

LACOSTE, Yves. A Geografia - Isso Serve, em Primeiro Lugar, Para Fazer a Guerra. Campinas: Editora Papirus, 2011 [1976]. 
MAQUIAVEL, Nicolau. O Príncipe. Rio de Janeiro: Nova Fronteira, 2011 [1532].

MATTOS, Cláudia Valladão de. (Org.). Goethe e Hackert - sobre pintura de paisagem: quadros da natureza na Europa e no Brasil. Cotia, SP: Ateliê Editorial, 2008.

MAURÍCIO, Carlos. Hobsbawm, ou quando o nacionalismo inventa a nação. In: Ler História [Online], Lisboa, n. 62, pp. 113-116,2012. Disponível em: https://journals.openedition.org/lerhistoria/604. Acesso em: 11 dez. 2020.

MORAES, Antônio Carlos Robert. Ratzel. São Paulo: Editora Ática, 1990.

OLWIG, Kenneth. The "Actual Landscape," or Actual Landscapes? In: DeLUE, Rachael; ELKINS, James. Landscape Theory - The Art Seminar, Volume VI. Nova Iorque e Londres: Routledge, 2008.

POHL, Walter. Barbarian migrations (Völkerwanderung). In: NESS, Immanuel (Ed.). The Encyclopedia of Global Human Migration. Hoboken, NJ: Blackwell Publishing Ltd, 2013. Disponível em: https://onlinelibrary.wiley.com/doi/abs/10.1002/9781444351071.wbeghm572. Acesso em 05 dez. 2020.

RECLUS, Éliseé. Do Sentimento da Natureza nas Sociedades Modernas. São Paulo: Editora Imaginário, 2010 [1866].

RODRIGUEZ, José Manoel Mateo; SILVA, Edson Vicente da. A Classificação das Paisagens a partir de uma Visão Geossistêmica. In: Mercator, Fortaleza, ano 1, n. 1, pp. 95-112, 2002.

SAUER, Carl. A Morfologia da Paisagem. In: CORREA, Roberto \& ROSENDAHL, Zeny. Paisagem, Tempo e Cultura. Rio de Janeiro: EdUERJ, 1998 [1925].

SAFRANSKI, Rüdiger. Romantismo: Uma questão alemã. São Paulo: Editora Estação Liberdade, 2010.

SCHAMA, Simon. Landscape and Memory. New York: Vintage Books, 1996.

WULF, Andrea. A Invenção da Natureza - as aventuras de Alexander von Humboldt. São Paulo: Editora Planeta, 2016. 